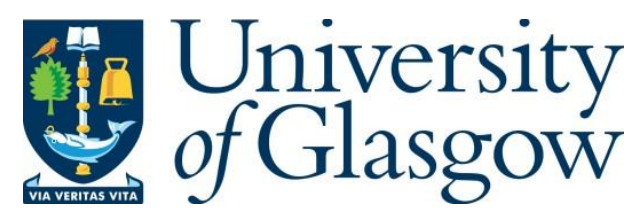

Zortea, T. C., Dickson, A., Gray, C. M. and O'Connor, R. C. (2019) Associations between experiences of disrupted attachments and suicidal thoughts and behaviours: an interpretative phenomenological analysis. Social Science and Medicine, 235, 112408. (doi:10.1016/j.socscimed.2019.112408)

There may be differences between this version and the published version. You are advised to consult the publisher's version if you wish to cite from it.

http://eprints.gla.ac.uk/190207/

Deposited on: 11 July 2019

Enlighten - Research publications by members of the University of Glasgow http://eprints.gla.ac.uk 


\section{Accepted Manuscript}

Associations between experiences of disrupted attachments and suicidal thoughts and behaviours: An interpretative phenomenological analysis

Tiago C. Zortea, Adele Dickson, Cindy M. Gray, Rory C. O'Connor

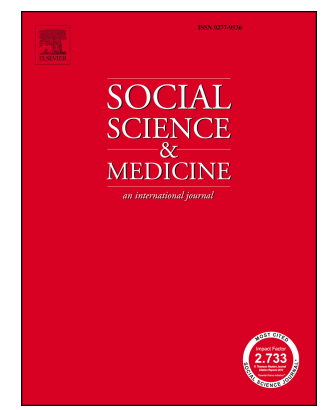

PII:

S0277-9536(19)30394-6

DOI:

https://doi.org/10.1016/j.socscimed.2019.112408

Article Number: 112408

Reference: SSM 112408

To appear in: Social Science \& Medicine

Received Date: 10 December 2018

Revised Date: 19 June 2019

Accepted Date: 7 July 2019

Please cite this article as: Zortea, T.C., Dickson, A., Gray, C.M., O'Connor, R.C., Associations between experiences of disrupted attachments and suicidal thoughts and behaviours: An interpretative phenomenological analysis, Social Science \& Medicine (2019), doi: https://doi.org/10.1016/ j.socscimed.2019.112408.

This is a PDF file of an unedited manuscript that has been accepted for publication. As a service to our customers we are providing this early version of the manuscript. The manuscript will undergo copyediting, typesetting, and review of the resulting proof before it is published in its final form. Please note that during the production process errors may be discovered which could affect the content, and all legal disclaimers that apply to the journal pertain. 


\title{
Associations between experiences of disrupted attachments and suicidal thoughts and \\ behaviours: An Interpretative Phenomenological Analysis
}

\author{
Tiago C. Zortea*
}

Suicidal Behaviour Research Laboratory, Institute of Health and Wellbeing, University of Glasgow, Academic Centre, Gartnavel Royal Hospital, 1055 Great Western Road, Glasgow G12 0XH, Scotland, United Kingdom. Email address: t.carlos-zortea.1@ research.gla.ac.uk. Telephone number: (44) 01412014469 * Corresponding author.

\section{Adele Dickson}

School of Health \& Life Sciences, Glasgow Caledonian University, 70 Cowcaddens Road, Glasgow, G4 0BA, Scotland, United Kingdom. Email address: Adele.Dickson@gcu.ac.uk.

\section{Cindy M. Gray}

Institute of Health and Wellbeing, Room 230, 25-29 Bute Gardens, University of Glasgow, Glasgow G12 8RS, Scotland, United Kingdom. Email address: Cindy.Gray@ glasgow.ac.uk.

\author{
Rory C. O'Connor
}

Suicidal Behaviour Research Laboratory, Institute of Health and Wellbeing, University of Glasgow, Academic Centre, Gartnavel Royal Hospital, 1055 Great Western Road, Glasgow G12 0XH, Scotland, United Kingdom. Email address: Rory.OConnor@ glasgow.ac.uk. 


\section{Introduction}

Suicide is a major global public health issue, and accounts for more deaths annually than wars and other methods of interpersonal violence combined (World Health Organization, 2014). Although there are several ways to understand the phenomena of suicidal thoughts and behaviours (STB), arguably suicide is most related to psychological factors (O'Connor \& Nock, 2014) as an individual makes a decision to end their life. There is therefore a need to understand how psychological mechanisms interact with environmental and developmental factors to reduce suicide risk.

Contemporary theoretical frameworks of STB have endeavoured to investigate the role of various psychological factors as drivers of suicidal behaviour. The Integrated Motivational-Volitional (IMV; O’Connor \& Kirtley, 2018) model is a diathesis-stress model focusing on the development of suicidal thinking and its transition to suicidal behaviour. The model endeavours to explain the pathway to suicidal behaviour through three phases: (1) a pre-motivational phase (background factors and triggering events) that describes the context in which suicide risk emerges including factors such as vulnerability, stressful events and environmental issues; (2) a motivational phase where suicidal thoughts and intent are formed via the key drivers of defeat and entrapment, and facilitated or obstructed by moderating variables; and (3) a volitional phase (behavioural enaction), which seeks to explain how suicidal thoughts are translated into a suicide attempt in the presence of volitional moderators: That is, factors that enable or reduce the likelihood of such transition. (O'Connor, 2011; O’Connor \& Kirtley, 2018). Within the motivational phase, emotion dysregulation and coping strategies are examples of moderating factors that may increase or decrease the likelihood of someone developing suicidal ideation via defeat and entrapment. Similarly, impulsivity has been suggested as a volitional moderator, facilitating the translation of suicidal thoughts into a suicide attempt (O'Connor \& Kirtley, 2018). 
The motivational phase of IMV model suggests that key components of the Interpersonal Theory of Suicide (Joiner, 2005; Van Orden et al., 2010), perceived burdensomeness and thwarted belongingness, increase the likelihood of entrapment escalating into suicidal thoughts. Perceptions of burdensomeness are characterised as the sense of being a burden to others, and thwarted belongingness includes feelings of loneliness, absence of reciprocally positive relationships and a lack of social support. While these psychological states have been strongly associated with suicidal ideation (Chu et al., 2017), interpersonal risk factors for suicidal thoughts are embedded in broader psychological structures that regulate perceptions, feelings, and attitudes towards personal relationships and emotional bonds (Venta, Mellick, Schatte, \& Sharp, 2014). As suggested by the anthropological literature on suicidal behaviour, what people do to themselves, they do to other people - both the causes and consequences of suicidal behaviour are relational (Staples \& Widger, 2012). Therefore, investigating such interpersonal structures and how they are related to STB is a crucial step for understanding psychological vulnerability for STB, and for planning and developing appropriate early intervention strategies.

Previous research focusing on the role of attachment as a risk factor for STB (Adam, 1986; 1994; Adam, Bouckoms, \& Streiner, 1982) draws from attachment theory (Ainsworth, Blehar, Waters, \& Wall, 1978; Ainsworth \& Bowlby, 1991; Bowlby, 1979, 1982, 1988; Bretherton, 1992) and suggests that insecure attachment orientations are related to psychological vulnerability for STB. According to attachment theory, being exposed to a disruptive parental environment during childhood (e.g., abusive, neglecting, inconsistent, violent, invalidating parenting) may lead to insecure forms of attachment (i.e., anxious, avoidant) and shape a child's negative perceptions of themselves and positive or negative perceptions of others. Ainsworth and Bowlby (1991) have posited that such perceptions become a child's main model or reference of interaction with the world, particularly within 
intimate relationships. Thus, a child's future relationship functionality will mostly be based on the model learned through their early interactions with parents or carers (Bowlby, 1988), and disrupted early attachments have been shown to be associated with systemic interpersonal dysregulation throughout the lifespan (for an extensive review of empirical studies, see Mikulincer \& Shaver, 2016a).

While existing models have extended our understanding about the impact of early disrupted family environments upon STB, they have largely been focussed on quantitative analyses, providing evidence that experiences with disrupted family relationships are associated with suicidal thoughts and behaviours (e.g., Brent et al., 1994; Campos, Besser, \& Blatt, 2013; Cruz, Narciso, Pereira, \& Sampaio, 2014; Donath, Graessel, Baier, Bleich, \& Hillemacher, 2014; Fergusson, Woodward, \& Horwood, 2000; GonzalezSeijo, Vicente, Martinez, Vega, \& Masia, 1996; Hardt, Herke, \& Schier, 2011; Heider et al., 2007; Wedig \& Nock, 2007). Examples of such associations include retrospective accounts of parents' rejection being associated with self-destructive thoughts and behaviours for adolescents (Cruz et al., 2014); lower levels of perceived parental love associated with high levels suicidal ideation among adults (Hardt et al., 2011); and perceptions of rejecting-neglecting parents associated with risk of suicide attempts among adolescents (Donath et al., 2014). Although empirical evidence supports the existence of such associations, it is still unknown why they are associated and how these early attachment experiences become risk factors for suicide later.

There is therefore an important gap in the evidence base, with qualitative investigations needed to gain a rich, in-depth understanding of the underlying mechanisms that account for the attachment and STB relationship. Bostik and Everall (2007), for instance, investigated young people's perceptions of attachment relationships as helping them to recover from STB. Employing a grounded theory approach, they found that recovery was 
associated with finding acceptance, having a permanent relationship, receiving encouragement, and experiencing intimacy in close relationships. However, there remains a dearth of research examining how psychological vulnerability for STB is developed from the perspective of those individuals who have experienced it.

The overall aim of the present study is to explore the nature of the relationship between attachment and STB in adults with a suicide attempt history. Specifically, we sought to investigate how those who have attempted suicide make sense of their experiences of STB, and to better understand the inter- and intra-personal catalysts of STB. Interpretative phenomenological analysis (IPA), which aims to understand individuals' personal perceptions, is an in-depth explorative research method to provides groundwork for understanding experience, while sustaining a reflective and critical stance (Smith, Flowers, \& Larkin, 2009). IPA is an idiographic approach, which is vital for capturing the personal meaning of participants' experiences.

\section{Method}

\section{Sampling}

A convenience sample of nine individuals (4 men, 5 women) who had attempted suicide at least once previously was recruited through advertising on social media (e.g., Twitter, Facebook, Gumtree, University website forum) from the general population. Suicide attempt was defined as a non-fatal, self-directed self-harming episode associated with at least some evidence of suicide intent (O’Connor, Smyth, Ferguson, Ryan, \& Williams, 2013). Inclusion criteria were: at least 18 years old; having attempted suicide previously, an attempt that required hospital admission; and being competent in English. Exclusion criteria were: being imminently suicidal (i.e., a person stating that they intended to kill themselves within the next few hours); experiencing a psychotic episode at the time of recruitment; and having a 
learning disability, mobility or cognitive impairment. Twenty-one people interested in taking part in the study contacted the research team, and nine met the inclusion criteria for participation. Participants were aged between 20 and 30 years $(M=24.5, S D=3.4)$; and came from various geographical locations in the UK. The age at which participants first thought about suicide ranged from 11 to 22 years $(M=15.7, S D=3.4)$ and the age when they first attempted suicide varied between 13 and 25 years $(M=17.4, S D=4)$. Further details on participants' demographic information and suicidal history appear in Table 1.

[Please Insert Table 1 here]

\section{Procedure and interview}

Ethical approval for the study was obtained from the relevant ethics committee of the College of Medical, Veterinary and Life Sciences (MVLS) at the University of Glasgow (application No 200160056). Potential participants contacted the first author via email and scheduled an eligibility screening telephone call. Prior to the telephone call, all potential participants were emailed the information sheet and a support sheet with a list of relevant organisations to contact should they require support (e.g., Samaritans, Breath Space; SAMH). All potential participants were given the opportunity to ask questions about the study.

The interviews were scheduled for eligible participants at their convenience. Semistructured face-to-face interviews were conducted by the first author at the Suicidal Behaviour Research Lab, audio recorded, and lasted between 45-65 minutes ( $M=50$ mins). No one else was present besides the participants and interviewer. All participants were offered $£ 30$ compensation for taking part. A topic guide was prepared to provide a framework for the interview based on the overall aim of the study. Each interview began with a general question 'Tell me about your experiences with suicidal thoughts and behaviours'. If personal relationships were considered important for the participants to make sense of their experiences, typical follow-up questions included 'How did that make you feel?' and 'What 
were you thinking about at that time?'. A semi-structured approach was used to allow the interviewer to guide each participant through their STB journey. To facilitate this process, a technique of reflecting and probing (e.g., 'You mentioned that... tell me a little bit more about that?') was adopted. The interviewer often requested detailed information to determine a more robust and insightful account of how the participants made sense of their experiences (Table A, Online Supplement). A risk assessment comprised of clinical measures of psychological distress and suicide intent was conducted after the interviews to ensure participants' safety. None of the participants indicated distress following in the interviews. All interviews were audio recorded on a digital voice recorder and were subsequently transcribed verbatim. Transcripts were not shared with participants prior to or following analysis.

\section{Analysis}

The interview transcripts were analysed using interpretative phenomenological analysis (IPA) (Smith et al., 2009; Smith \& Osborn, 2003). IPA is an inductive, qualitative approach that typically uses small numbers of participants to allow in-depth investigation of each participant's particular lived experience of a specific event (phenomenology), the significance they attribute to that event and how they account for the experience (idiographic account) (Smith et al., 2009). The process of making sense of an experience is a fundamental theoretical element of IPA, which posits that an experience can be understood through examination of the meanings that people impress upon it (Smith et al., 2009). IPA is deeply interpretative (uses hermeneutics) and recognises the researcher's preconceptions and analytical engagement with the transcripts. IPA was employed herein as it combines phenomenological and hermeneutic insights, allowing an exploration of the connections between what participants say and the way in which they make sense of their own experiences. 
Following Smith et al.'s (2009) guidelines, the transcripts were coded as follows: 1) reading and re-reading each interview transcript; 2) making notes focusing on the semantic content and the language used by the participant; 3) developing emerging themes through description and interpretation of the data; 4) investigating the connections between these emergent themes; 5) repeating the aforementioned stages with the next interview transcript; 6) searching for patterns across the transcripts to develop a major set of emergent themes ('Master themes' or 'Superordinate themes'). Although IPA prioritises small sample sizes to allow in-depth investigation of each participant's particular lived experience of a specific event (Smith et al., 2009), towards the end of data collection no new information emerged from the data. Therefore, data saturation was considered to have been reached.

In terms of the analytic process, several themes emerged within individual transcripts and when the same themes were reported across multiple transcripts, they were categorised as being recurrent and clustered into master themes. This approach allows an idiographic perspective to be captured that is counterbalanced with a more general, shared perspective within the data. The first two authors independently produced exploratory emergent themes and master themes for four transcripts and compared notes. The first author subsequently coded the remaining transcripts. All analysis was conducted by hand. Thereafter, the first and third authors independently produced exploratory emergent themes and master themes for two transcripts and compared notes. Finally, the first three authors identified emergent themes and master themes separately and decided on a final list of master themes. The following Master themes derived from the data were identified: 'Onset of symptomatology', 'Drivers to STB', 'Barriers/Protecting factors to STB', 'Coping strategies', 'Challenging Relationships as Catalysts for STB' and 'Positive Relationships as Buffers against STB' (Table B, Online Supplement). The analysis presented in this study focuses on the two latter Master themes, as they allow us to deepen our understanding on the role of attachment 
mechanisms in the onset and buffering of STB. Identities from all interviews use pseudonyms.

\section{Research Team and Reflexivity}

The interviews were conducted by the first author, who is a male clinical psychologist undertaking a PhD. He attended an IPA training workshop focused on data collection and analysis. The study was supervised by the co-authors: the second author is an IPA expert, the third author a qualitative research expert, and the last author is a health psychologist who has been conducting research on suicide for more than 20 years. No relationship was established between researcher and participants prior to study commencement. The only information disclosed to the participants about the researcher was the institution affiliation and that he was conducting a study on lived experiences of suicidal behaviour. No characteristics were reported about the interviewer. The first author kept a reflective journal/diary to reflect on his thoughts throughout the process and often shared these with the wider team for discussion. Participants were offered a one-page anonymised summary of the key research findings at the end of the study.

\section{Results}

\section{Challenging Relationships as Catalysts for STB}

All participants reported their perceptions of the influences of challenging relationships on the aetiology of their mental health, suicidal ideation, and suicide attempt(s) (Table C, Online Supplement). They described how their STB were associated with perceived prolonged exposure to inescapable turbulent relationships in which they felt other people's behaviours had negatively impacted their psychological wellbeing. With the exception of one participant (Leon), all highlighted how the relationship with their parents (or with one of them) contributed to the development of their psychological issues, suicidal ideation, and 
suicide attempts.

More specifically, eight out of nine participants reported feeling unimportant, worthless or invalidated as a consequence of complex and turbulent family dynamics during their childhood and adolescence. A broad range of retrospective accounts of negative parental behaviours was reported, including perceived neglect, dismissiveness, abandonment, verbal abuse, physical violence, rejection and invalidating attitudes. Emily (age 29) provides an example of such experiences:

I remember being about five or six and not being able to buckle my shoes up fast enough and that just...like [my mother] throwing me around the room. My parents were together until I was 15 but my dad worked really long hours, like 14-hour days on the dock. So, I don't think he actually knew. So, I'm not really sure what went on, but she [mother] would be quite verbally abusive as well. I don't know why you'd call a small child a selfish bitch and a stupid cow, I didn't really understand at that age. And I remember her going: "aren't you ashamed?" And at that age I thought I didn't know what I'd done wrong, and I thought “oh, I better say yes because then she won't hit me again". But then I thought "I can't say no because that's lying" and we were brought up Christians, things like that.

Emily's account describes a turbulent, highly aversive, and unpredictable parental environment. Her extract is peppered with an ongoing sense of continuous threat and unjust punishment, torment, and abuse. Here, Emily struggles to make sense of her situation, and she appears particularly innocent, vulnerable, and powerless. Emily's reference to her father and her ambivalence as to whether he was aware of her mother's abuse is also of interest here. We ponder whether Emily's tentative, doubtful account intends to protect her father (and her relationship with him) or herself from the realisation of further neglect. It is possible that this served as a self-preservation mechanism for Emily - considering the possibility of her father's indirect involvement would be unbearable. Either way, eight participants provided accounts of unpredictable, abusive, invalidating parental environments, and a lack of control over such contexts driving a vast array of long-lasting psychological effects. 
Eight out of nine participants also described how perceived parental abuse fuelled feelings of self-hatred, rejection, worthlessness, and isolation. Such psychological processes seem to have been compounded by other unstable influential relationships elsewhere, reinforcing negative views of the self and feelings of inescapability. Across the interviews, participants highlighted that such experiences served as catalysts for suicidal thoughts, selfharm, and suicide attempts, as the following account from Joanne (age 22) illustrates:

I don't trust anyone because I know that people are going to leave. Like my mum left me in the middle of a road, in a car, so she's done that, and she's apparently meant to love me, then what are other people going to do? [...] so, it's just easier not connecting with someone and just sticking by yourself. If somebody ran me over tomorrow, I'd be pretty ready to go, like, I wouldn't fight it. Like, I'm completely done because everyone's just leaving. There's got to be something wrong with me and I don't know what it is, that's the thing because everyone says that it's not me, but the common factor in everything that's happened it's me.

Joanne's hopelessness and cynicism about close relationships are evident. Her memories of traumatic maternal abandonment, neglect, and abuse appear to have contributed to a failure to secure positive, successful, and lasting adult relationships. According to Joanne's deeply reflective account, the quest for fruitful relationships are perceived as relentless, futile and cyclical. Joanne appears to have no control over the success of healthy adult relationships, which seems to contribute to a desperate search for responses and solutions. Equally important is the process of reinforcement of those negative views about relationships through unstable relationships in later life: not connecting with anyone seems to be a response to how Joanne feels - a sense of being abandoned by all. The emotional costs involved in searching for answers, the lack of support, and the sense of failure in finding a solution seem to be strongly connected with her isolation and wish to die, perceiving death as a final escape from the unbearable interpersonal problems that, in her mind, she is part of the cause.

Joanne's account was reflected by the seven other participants (the exception was Leon). Such feelings were so intense that participants described a sense of inescapability, 
perceiving suicide as an ultimate solution to regaining control over their lives and ending unbearable psychological pain. Christina's (age 23) quote regarding her suicidal thoughts and attempt elucidate this process:

My parents were, like, very abusive to one another and also to me, and that pushed me out of the home, like, from quite an early age anyways. So I was, like, getting into bad stuff, like getting into drugs at the age of 13 and with that came other unpleasant things. So yeah, I felt like I was in this circle, I just felt a bit trapped by life, like, also having... not liking being inside my own brain even, so it's not even like I had a safe space inside myself, it was, kind of, like, didn't really like myself either, because I didn't like being, yeah, trapped in my brain type thing, I wanted to shut that off, yeah.

Christina's account represents an experience shared by most (eight) participants: a feeling of being entombed within an endless cycle of perceived unsolvable relationship problems characterised by an absence of social support and no means of escape. Yet, Christina also describes a profound sense of danger from within her own body - she is ensnared by her own precarious thoughts and there is no capacity to seek refuge either physically or mentally. Christina perceived suicide as the only means of escape from a systemic perception of feeling overwhelmed and defeated by adverse life circumstances, experiencing hopelessness, and entrapment compounded by interrelated external and internal uncontrollable problems. This experience is further captured by Matt's (age 27) description:

I had no friends, I had no family and, you know, I'd weighed up all the consequences and the paths and I really couldn't see me living or dying making any impact. I was so depressed at the time and so hopeless at the time if...then I might as well just go and turn off the lights because it would be easier for me and it's not like I'd be leaving much behind.

Matt's account transmits a sense of suicide being his only possible exit path. Here, he describes his unsuccessful search for alternative solutions, and a rational, conscious decisionmaking process leading to suicide. There is a sense of Matt being invisible in life (and therefore also in death) and the absence of a reason to live appears to finalise his decisionmaking in relation to suicide. Matt's metaphor for suicide 'turning off the lights' seems to suggest a way in which he can take back control, a means of escaping such unsolvable issues. 
Perhaps for Matt, suicide would mean he no longer had to see or face the feelings of being insignificant, invisible and worthless. Although these are Matt's words, they represent the narrative of all participants, where the prolonged exposure to what they perceive as invalidating relationships facilitated the development of a psychological vulnerability for STB.

Although most participants described challenging relationships with their parents as being central to their vulnerability for suicidal behaviour, there was an acknowledgement that these did not exist in isolation. Often, participants reported experiencing other simultaneously challenging relationships (e.g., with partners, school peers) that further exacerbated their vulnerability. For some participants, such experiences included bullying $(n=8)$, sexual harassment $(n=3)$, and the break-up of romantic relationships $(n=5)$. These were said to directly relate to their suicidal thoughts and attempts. Laura's (age 22) experience provides an example of how the traumatic end of a romantic relationship escalated into a suicidal crisis:

He said that I was a bitch and that I was clingy and possessive and that I was a burden on everyone. [...]. The next day we got up and I tried to speak to him about our relationship and he kicked me out his flat. So, he completely pushed me out his door and shut the door on me. And I went home and that's when I just felt like I didn't want to be hurting and I didn't want to be in so much pain. And I felt like I was... "am I that bad a person for someone to just kick me out of their house and not want to see my face?" And that's when I [attempted suicide]. Laura's unanticipated experience of rejection appeared to trigger overwhelming emotional pain and served as further perceived confirmation of being undesirable, negligible, and worthy of dismissal. Laura assumes personal responsibility for the failure of the relationship and her suicidal crisis emerged from her perceived accountability and sense of helplessness. It is as though this one final source of rejection was the last straw for Laura - she had reached breaking point, the end of the line, and there was no other path in sight. Indeed, eight out of nine participants shared similar feelings of intense invalidating relationships that reinforced 
negative self-perceptions, thoughts, memories and emotions. For these participants, suicide provided an opportunity to reclaim control.

\section{Positive Relationships as Buffers against STB}

Eight participants (with exception of Joanne) also highlighted how positive relationships contributed to the development of resilience and wellbeing. Through experiencing subsequent positive relationships later in life, participants reported that they developed healthier coping strategies and the ability to openly express their feelings. Positive and (mainly) reciprocal romantic relationships in adulthood appeared pivotal to re-building self-worth and self-acceptance. When describing the importance of positive romantic relationships, participants highlighted a sense of respect and being cared for, being accepted despite their mental health issues, attitudes of reciprocity, and a change of self-perceptions.

As Claire describes, these experiences were viewed as key influential elements on participants' recovery:

He [boyfriend] gave 180 degrees to my life, because first he never imposed himself on me. In the past, people would always try to manipulate me as they wanted and they would help me in the way they wanted. In this time, my boyfriend would actually notice what was going on with me and approached me the way I wanted to. He is patient, he would wait... and even though I kept pushing him away, he would come and stay. And then, after that I realised "you know what? I am worth it, and not only for him, but also worth it for me". And then I realised, after all these years, I was always expecting someone to take care of me and that's why I was so low instead of me standing up for myself. And being here [giving the interview] also helps me, being by myself, I understood what I actually like, and what I feel comfortable doing by myself. Yeah, I'm not very social, but that is okay, because that is me. My boyfriend respect that a lot.

Claire's account highlights the transitional force of one continuous, reciprocal, and unconditional romantic relationship - she is suddenly visible, heard and entirely accepted for who she is. As with three other participants, this positive and validating relationship appears to drive a reinterpretation of the past and a sudden change in self-perception. It is as though 
Claire is seeing herself for the first time through a new lens - affording her a newfound sense of self-respect, self-compassion, and self-confidence. The sense of ongoing unconditional acceptance from her fiancé coupled with respect for her own time, space and needs seem to have been life-changing for Claire - this Claire is a stark contrast to the old Claire - this Claire has regained control of her life.

Three participants highlighted how perceived reciprocity in their romantic relationships contributed to their recovery. However, two also reported a sense of responsibility and a duty of care for their partner's needs and wellbeing. Chris (age 20) describes how a need to protect his girlfriend superseded any STB:

I know for a fact that if I was gone that wouldn't be good for her, because she's told me bloody enough times and because she's had enough like in her life and enough pain coming through, everything she's gone through that... I don't want to do that to her anymore, so she thinks that I need to be here, I need to be here.

Chris's account highlights that one positive, meaningful relationship may serve as a commanding driver for preserving life when people experience suicidal feelings. It is as though his girlfriend acts as a 'life line' for Chris, giving him purpose in life that displaces his deepest, darkest thoughts. While two other participants' accounts echoed this theme, we also question whether dependency on one such positive relationship may create additional vulnerability for participants. There is the notion of Chris's mental health as still being fragile - he, like many other participants, still experiences suicidal thoughts and urges. If one romantic relationship provides the sole purpose for life, what would occur should that relationship no longer exist? In this context, we consider whether the termination of such a powerful protective relationship would very rapidly become a powerful precipitant for suicidal behaviour.

In addition to positive romantic relationships, eight participants spoke of other positive relationships and their role in promoting for recovery or managing suicidal thoughts. Reciprocal contribution to friendships emerged as another key protective factor. For some, 
such as Emily (age 29), reciprocal, meaningful friendships promoted a sense of shared vulnerability, empathy and support:

He's one of my closest friends at the moment, and he's very understanding. I just feel like I can talk to him about anything and we have really interesting discussions and reflections. I think he's maybe not the most extrovert person ever, like socially capable of engaging in big groups or strangers or parties or anything, I kind of feel the same. So, I think he almost depends on me to get him out the house as much as I depend on him.

The non-judgemental nature of this relationship appeared to facilitate a tentative process of Emily 'opening up'- here there is a sense that she is cautiously exposing her true self to others. This extract, like those that have come before, is peppered with vulnerability and fragility, but the mutual dependency and trust that is shared here between Emily and her friend gives strength and courage and promotes self-acceptance and self-growth. Like Emily, seven other participants acknowledged meaningful, positive relationships as being crucial for self-improvement, healing and self-growth. While it was acknowledged that exposing oneself to such relationships was precarious, we conclude with a powerful extract from Matt that encapsulates the cherished nature of positive relationships and their prized place in participants' worlds:

I learnt to be able to talk to others and depend on others and sometimes it still bites you in the arse. I think that's the nature of it but I've learnt... you know, the alternative is not better. I mean once I started opening myself up and allowing myself to not see relationships as a weakness but a huge strength my life is, you know, a million-fold, if...you know, if not more better. It's liveable, it's...that's the difference, is life is liveable and it's worth living and that's the enduring thing that keeps me going now, is even when I'm still feeling...if I still have a...if I have a drop, or anything like that, I never lost the knowledge that life is inherently good and that people...I don't think people are inherently good but I think they're...there's inherent good in them and I don't know if I would be able to see that without seeing the reverse.

Additional analysis appears in Table C (Online Supplements). 


\section{Discussion}

In this article, we have presented the experiences of challenging and positive relationships by people who have previously attempted suicide. To our knowledge, this study is the first to present an idiographic, hermeneutic, phenomenologically informed account to better understand the mechanisms that may explain the relationship between early and current attachment experiences and the vulnerability for STB. Across the interviews, the participants highlighted how challenging relationships contributed to the development of psychological vulnerability for STB, and how positive relationships contributed to the development of resilience, recovery and mitigation of suicidal thinking. Figure 1 represents the thematic map that arose from the results, which are discussed below under each master theme's subheading.

[Please insert Figure 1 around here]

\section{Challenging Relationships as Catalysts for STB}

Although challenging relationships in general were related to the aetiology of STB, almost all participants perceived early disrupted relationships with their parents and family as critical factors associated with their psychological vulnerability for STB. Our participants reported memories of being exposed to prolonged and uncontrollable invalidating family environments, similar to those described by Linehan (Linehan, 1993), in which parents punish, trivialise and disregard their children's emotional and personal difficulties. Studies have demonstrated that such negative perceptions of early experiences are associated with the development of a series of mental health issues including alexithymic tendencies (difficulties in identifing and describing emotions in the self (Kench \& Irwin, 2000), which has also been shown to be associated with suicidal thoughts (Hemming et al., 2019)), borderline personality symptoms (Schuppert, Albers, Minderaa, Emmelkamp, \& Nauta, 2015), and self-harm (Baetens et al., 2015; Burešová, Bartošová, \& Čerňák, 2015). 
Our study also sheds light on potential psychological mechanisms that may explain connections between perceptions of early childhood adverse family experiences and later suicidal behaviour. Specifically, an early internal model of abusive, dismissing, and invalidating relationships appears to be internalised, forming long-lasting, deep psychological scarring. Perceived early disrupted attachment seem to have shaped the participants' interpretations and behaviours regarding their relationships (Bowlby, 1982, 1988), which in turn seems to have contributed to the development of vulnerability for later STB.

Similar to Adam's model (1986), our findings suggest that disrupted early attachments, prolonged invalidating family environments and lack of a secure base, may lead to the recurrent patterns of attachment problems, where extreme desire for closeness (anxious attachment) and emotional withdrawal (avoidance attachment) exert excessive demands on crucial relationships, contributing to their breakdown. These processes are evident across the interviews: 1) the recognition of the influences of early attachment issues, 2) the generalisation of such attachment patterns to other intimate relationships, and 3) the persistence of attachment difficulties (attributing the cause of the relationship problems to the self). Such a process was hypothesised by Bowlby (1988) as a chain of adverse events that is more likely to occur for those with memories of disrupted attachment experiences. Given that the age thought to be of most importance in terms of attachment experiences (0-2yrs; Trad, 1994) is a time when most people are unable to recall, it is important to highlight that the participants' accounts represent their sense making of their experiences and may not reflect the facts objectively.

The participants' accounts in the current study allow us to understand how vulnerability is shaped, and the attachment system seems to be a key component for such understanding. Many studies have demonstrated how insecure attachment orientations affect interpersonal regulation (Mikulincer \& Shaver, 2016a) through: increasing inconsistencies 
among interpersonal goals (Locke, 2008), worsening trust issues (Mikulincer, 1998), intensifying rumination (Saffrey \& Ehrenberg, 2007), deteriorating conflict management skills (Mikulincer \& Shaver, 2011), loneliness and social isolation (Larose, Guay, \& Boivin, 2002), and a series of other difficulties in interpersonal regulation (Mikulincer \& Shaver, 2016a). Adam (1986, 1973, 1994) suggests that individuals who experience early disrupted attachment are not only more susceptible to form insecure relationships later in life, but they are overly sensitive to threats to their maintenance, reacting strongly with the activation of separation or abandonment anxiety of which suicidal thinking may be one element.

Exploring the effect of insecure forms of attachment, a previous qualitative study (Benson et al., 2016) has suggested that developmental narratives including a range of challenging family relationships seemed to have compromised the participants' ability to trust others. These narratives also seem to affect participants' sense of self-worth, precluding safe exploration and interpretation of feelings and interests from which meaningful and valuable experiences could develop. These findings resonate with some of our participants' accounts (e.g., Joanne) in which their views of the self and others appear to be biased by their perceptions of past experiences with challenging relationships, compromising the functioning of the attachment system, thereby facilitating suicide risk. Although STB are affected by a complex interactive network of factors (de Beurs, 2017), Adam (1986) proposes that a suicidal crisis may have the unconscious function of communicating psychological distress and re-establishing a desired and needed interpersonal bond. Although insecure forms of attachment alone may not be sufficient catalysts for a suicide attempt, their presence heightens the likelihood of self-directed aggression (Trad, 1994). Therefore, as a psychological vulnerability factor indirectly related to STB, insecure forms of attachment seem to aggravate the intensity of participants' perceptions of adverse life experiences, increasing the likelihood of STB. 
When referring to experiences immediately prior to their suicide attempt, the majority of participants in the current study reported experiencing hopelessness and a sense of being entrapped by their problems. These narratives were also found evident in a qualitative study in which participants described feeling 'trapped in an overwhelming situation' (Crona, Stenmarker, Öjehagen, Hallberg, \& Brådvik, 2017). In our study, such experiences of entrapment/inescapability were related to feelings of isolation, worthless, and rejection, providing support for the IMV model (O’Connor, 2011; O’Connor \& Kirtley, 2018). These findings suggest that, experiencing defeat, perceived lack of social support and thwarted belongingness (Joiner, 2005; Van Orden et al., 2010) act as motivational moderators, increasing the likelihood of entrapment escalating into suicidal ideation and intent. The persistent blocked view of potential solutions and the precluded possibilities restricting the desire for movement and escape (Gilbert \& Allan, 1998) would increase the odds of a suicidal crisis developing, which was observed across the participants' accounts. In our study, suicidal behaviour seems to exert two interrelated functions: regaining control of perceived unsolvable problematic life situations and escaping from emotional pain. These findings resonate with Jobes and Mann's (1999) clinical study in which they found that various forms of escape are the driving force underpinning suicidal behaviour.

Also present in our participants' accounts, perceived burdensomeness and thwarted belongingness, key components of the Interpersonal Theory of Suicide (Joiner, 2005; Van Orden et al., 2010), are strongly associated with the development of suicide intent (Chu et al., 2017). As perceived burdensomeness and thwarted belongingness involve intra- and interpersonal domains, Venta et al. (2014) have suggested that these factors may represent cognitions deriving from an insecure attachment-related structure. Therefore, we hypothesise that perceived burdensomeness and thwarted belongingness will have a particularly strong 
effect on the relationship between entrapment and suicidal ideation when people remember experiencing disrupted attachments in the past.

\section{Positive Relationships as Buffers against STB}

In our study, all participants reported the beneficial impact of positive intimate relationships on their mental health. Although a systematic review (Zortea et al., 2018) has identified secure attachment as a protective factor against STB, the findings of the current study suggest that positive and reciprocal intimate relationships may promote recovery and attenuate suicidal tendencies for those with insecure attachment orientations. Our participants' narratives of positive intimate relationships involved: 1) descriptions of their attachment figures' attitudes/behaviours, 2) their subsequent feelings and interpersonal reactions, and 3) their reflections and self-evaluation upon their own personal qualities and worthiness. A range of experimental studies in adult attachment have demonstrated the positive effect of understanding, validating and caring relationships in diminishing the impact of people's negative internal working models on their mental health, through increasing enduring positive thoughts and feelings about the self (see Mikulincer and Shaver (2016b) for an extensive review).

Most participants in the current study also reported a change in the way they perceived themselves as a function of these positive reciprocal relationships. These findings provide support for Baccus and colleagues' (2004) findings that when people think about themselves, involuntary representations of others' responsiveness can enhance their positive self-evaluations, suggesting an interdependence between the view of the self and others and, therefore, the positive impact of others' availability and responsiveness. Although other quantitative studies report evidence of the positive impact of intimate relationships on adult attachment (e.g., Arndt, Schimel, Greenberg, \& Pyszczynski, 2002; Baccus et al., 2004; Selcuk, Zayas, Günaydin, Hazan, \& Kross, 2012; Chang, Chan, \& Yip, 2017), the current 
study provides an in-depth description and interpretative account of participants' experiences, highlighting ideographically the psychosocial and interpersonal factors involved in their recovery.

In our study, positive relationships were described as respectful, caring, unconditionally accepting, reciprocal, trustful, and non-judgemental. These features echo a previous qualitative study that interviewed 50 adolescents who had attempted suicide about their perceptions of attachment relationships (Bostik and Everall 2007). Here, positive relationships were described as accepting, permanent, encouraging, supportive, intimate and close. Similar to our study, Bostik and Everall (2007) also reported that these relationship qualities appeared to be pivotal elements for changing negative self-perceptions and harmful emotional and cognitive states, and for providing hope and meaning to their recovery.

One possible way to understand the role of attachment relationships in the process of recovering from STB is through the development of resilience (Figure 1). In the current study, the participants highlighted that being exposed to positive relationships increased several aspects of their positive self-evaluation and personal wellbeing, including the capacity to deal with adversities (resilience), which, in turn, reduces vulnerability for mental health issues and suicide risk. These findings resonate with Karreman and Vingerhoets's (2012) study that indicates that secure attachment relationships increase psychological wellbeing through resilience. Future qualitative inquiries should focus on how the mechanisms of recovery involved in experiences of positive relationships work.

It is important to mention that for some participants, it is still possible to recognise the presence of vulnerability through emotional dependency on a single person (e.g., partner). This issue raises questions about what factors deactivate vulnerability and promote psychological recovery. Although Bowlby (1988) suggested that resilience against stressful life events is determined to a very significant degree by early attachment, recent research has 
shown promising results on the development of resilience through later attachment

(Mikulincer \& Shaver, 2016c). For example, intimate, positive attachment relationships during adolescence and adulthood have been shown to be associated with greater self-worth (e.g., Leary \& Guadagno, 2011), reduction of relational worries (about being rejected, criticised, or abused) (e.g., Murray, 2005), a greater sense of independence, increased selfefficacy in goal achievement and enhanced engagement in autonomous exploration (nonattachment-related behaviours) (Feeney, 2007). Irrespective of such promising evidence, it is worth highlighting the delicate nature of these relationships, as some participants indicated their life literally depending on such relationships. Although a positive and meaningful relationship seems to serve as a life-line for many participants pulling them from the depths of their suicidal thoughts, there is a sense that if these relationships were to end, the participants would be plunged back into the depths.

The current study also raises important questions that should be addressed in future research on the connections between family relationships, disrupted attachment and suicide risk: What are the elements of family environment that bring about experiences of comparative worthlessness and the lack of being understood that seem to be so powerful in explaining STB? How are other non-family factors that contribute to STB related to these? Further investigations directed at understanding of the specific effects of family relationships on psychological vulnerability may have important implications for suicide prevention and clinical practices.

\section{Strengths and Limitations}

Conclusions drawn from the findings of the current study must be interpreted along with the limitations. The theoretical generalisability of the current study is limited to other predominantly young populations and may not apply to other populations. Of course, it sampled individuals who had survived a suicide attempt; it is not clear that trends for them 
would generalize to those who succeed at suicide. As the current study is about people's perceptions of their own experiences and not objective facts, those retrospective accounts

may be subject to memory biases (e.g., selective recall of negative events and tendency to reinterpret memories in a negative way). The experiences that led to suicidal thoughts and behaviours were overall very similar and gender differences did not emerge as key factors for weighting the findings. It is noteworthy that the interpretative nature of the current analysis is subject to variability as it carries the authors' understanding of the phenomenon explored. Since IPA employs an idiographic approach, it prioritises depth over breadth through the accounts of smaller samples, appropriate for an in-depth analysis of the data. Therefore, IPA is a powerful methodological approach to understand the relationship between attachment and STB. The current study also provides theoretical contributions to the field of suicide research by highlighting how secure and insecure forms of attachment may be associated with suicide risk via resilience factors and psychological vulnerability factors consistent with the central tenets of the IMV model and IPT (Figure 1).

\section{Clinical Implications}

The findings of the current study convey some important clinical implications. First, in the context of psychological and psychiatric treatment of STB, an in-depth assessment of an individual's attachment orientations, internal working models, and close relationship dynamics would provide insight into intra- and inter-personal psychological vulnerability factors. Second, such comprehensive evaluation may also indicate the contextual factors related to the exacerbation of the underlying psychological vulnerability, which, in turn, may be strongly connected to STB risk factors such as defeat, social withdrawal, perceived burdensomeness, failed belongingness, entrapment, and emotion dysregulation. Third, our findings indicate that developing social and interpersonal skills would help the patient to reduce the impact of social anxiety and avoidance. The combination of interpersonal skills 
development and engaging with social groups would increase social interaction, reduce isolation and enhance the odds of experiencing belongingness, self-worth and acceptance. Finally, considering the presence of vulnerability through emotional dependency on a single intimate relationship suggests the need for ongoing psychological support, as a potential end of such relationships could trigger a new suicidal crisis.

\section{Conclusions}

This study explored the influence of challenging attachment relationships on vulnerability for STB and the effect of positive attachment relationships upon recovery from and mitigation of STB. Our findings provide support for the IMV model of suicidal behaviour, indicating that early disrupted attachments contribute to vulnerability for STB by shaping participants' perceptions of intimate others and themselves, which, along with other environmental factors and life events, may increase risk of STB through perceptions of defeat, entrapment, burdensomeness and thwarted belongingness. Importantly, however, our findings also indicate that exposure to respectful, caring, unconditionally accepting, reciprocate, trustful, and non-judgemental intimate attachment relationships in later life seem to be associated with recovery from past STB and a reduction of suicide risk. 


\section{References}

Adam, K.S., 1973. Childhood parental loss, suicidal ideation and suicidal behavior, in: Anthony, E.J. (Ed.), The Child in His Family: The Impact of Disease and Death. Wiley, New York, pp. 275-297.

Adam, K.S., 1986. Early family influences on suicidal behavior. Ann. N. Y. Acad. Sci. 487, 63-76. https://doi.org/10.1111/j.1749-6632.1986.tb27886.x

Adam, K.S., 1994. Suicidal behavior and attachment: A developmental model, in: Sperling, M.B., Berman, W.H. (Eds.), Attachment in Adults: Clinical and Developmental Perspectives. Guilford Press, New York, pp. 275-298.

Adam, K.S., Bouckoms, A., Streiner, D., 1982. Parental loss and family stability in attempted suicide. Arch. Gen. Psychiatry 39, 1081-1085. https://doi.org/10.1001/archpsyc.1982.04290090065013

Ainsworth, M.D.S., Blehar, M.C., Waters, E., Wall, S., 1978. Patterns of Attachment: A Psychological Study of the Strange Situation. Lawrence Erlbaum Associates, Hillsdale, NJ.

Ainsworth, M.D.S., Bowlby, J., 1991. An ethological approach to personality development. Am. Psychol. 46, 333-341.

Arndt, J., Schimel, J., Greenberg, J., Pyszczynski, T., 2002. The Intrinsic Self and Defensiveness: Evidence that Activating the Intrinsic Self Reduces Self-Handicapping and Conformity. Personal. Soc. Psychol. Bull. 28, 671-683. https://doi.org/10.1177/0146167202288011

Baccus, J.R., Baldwin, M.W., Packer, D.J., 2004. Increasing implicit self-esteem through classical conditioning. Psychol. Sci. 15, 498-502. https://doi.org/10.1111/j.09567976.2004.00708.x

Baetens, I., Claes, L., Hasking, P., Smits, D., Grietens, H., Onghena, P., Martin, G., 2015. The Relationship Between Parental Expressed Emotions and Non-suicidal Self-injury: The Mediating Roles of Self-criticism and Depression. J. Child Fam. Stud. 24, 491-498. https://doi.org/10.1007/s10826-013-9861-8

Benson, O., Gibson, S., Boden, Z.V.R., Owen, G., 2016. Exhausted without trust and inherent worth: A model of the suicide process based on experiential accounts. Soc. Sci. Med. 163, 126-134. https://doi.org/10.1016/j.socscimed.2016.06.045 
Bostik, K.E., Everall, R.D., 2007. Healing from suicide: adolescent perceptions of attachment relationships. Br. J. Guid. Counc. 35, 79-96. https://doi.org/10.1080/03069880601106815

Bowlby, J., 1979. The making and breaking of affectional bonds. Tavistock, London.

Bowlby, J., 1982. Attachment and loss: Volume 1, 2nd ed. Basic Books, New York.

Bowlby, J., 1988. Developmental psychiatry comes of age. Am. J. Psychiatry 145, 1-10. https://doi.org/10.1176/ajp.145.1.1

Brent, D.A., Perper, J.A., Moritz, G., Liotus, L., Schweers, J., Balach, L., Roth, C., 1994. Familial risk factors for adolescent suicide: a case-control study. Acta Psychiatr. Scand. 89, 52-58. https://doi.org/10.1111/j.1600-0447.1994.tb01485.x

Bretherton, I., 1992. The origins of attachment theory: John Bowlby and Mary Ainsworth. Dev. Psychol. 28, 759-775.

Burešová, I., Bartošová, K., Čerňák, M., 2015. Connection between Parenting Styles and Self-harm in Adolescence. Procedia - Soc. Behav. Sci. 171, 1106-1113. https://doi.org/10.1016/J.SBSPRO.2015.01.272

Campos, R.C., Besser, A., Blatt, S.J., 2013. Recollections of Parental Rejection, SelfCriticism and Depression in Suicidality. Arch. Suicide Res. 17, 58-74. https://doi.org/10.1080/13811118.2013.748416

Chang, Q., Chan, C.H., Yip, P.S.F., 2017. A meta-analytic review on social relationships and suicidal ideation among older adults. Soc. Sci. Med. 191, 65-76. https://doi.org/10.1016/j.socscimed.2017.09.003

Chu, C., Buchman-Schmitt, J.M., Stanley, I.H., Hom, M.A., Tucker, R.P., Hagan, C.R., Rogers, M.L., Podlogar, M.C., Chiurliza, B., Ringer, F.B., Michaels, M.S., Patros, C.H.G., Joiner, T.E., 2017. The interpersonal theory of suicide: A systematic review and meta-analysis of a decade of cross-national research. Psychol. Bull. 143, 1313-1345. https://doi.org/10.1037/bul0000123

Crona, L., Stenmarker, M., Öjehagen, A., Hallberg, U., Brådvik, L., 2017. Taking care of oneself by regaining control - a key to continue living four to five decades after a suicide attempt in severe depression. BMC Psychiatry 17, 69. https://doi.org/10.1186/s12888017-1223-4 
Cruz, D., Narciso, I., Pereira, C.R., Sampaio, D., 2014. Risk Trajectories of Self-

Destructiveness in Adolescence: Family Core Influences. J. Child Fam. Stud. 23, 11721181. https://doi.org/10.1007/s10826-013-9777-3

de Beurs, D., 2017. Network Analysis: A Novel Approach to Understand Suicidal Behaviour. Int. J. Environ. Res. Public Health 14, 219. https://doi.org/10.3390/ijerph14030219

Donath, C., Graessel, E., Baier, D., Bleich, S., Hillemacher, T., 2014. Is parenting style a predictor of suicide attempts in a representative sample of adolescents? BMC Pediatr. 14, 1-13. https://doi.org/10.1186/1471-2431-14-113

Feeney, B.C., 2007. The dependency paradox in close relationships: Accepting dependence promotes independence. J. Pers. Soc. Psychol. 92, 268-285. https://doi.org/10.1037/0022-3514.92.2.268

Fergusson, D.M., Woodward, L.J., Horwood, L.J., 2000. Risk factors and life processes associated with the onset of suicidal behaviour during adolescence and early adulthood. Psychol. Med. 30, 23-39. https://doi.org/10.1017/S003329179900135X

Gilbert, P., Allan, S., 1998. The role of defeat and entrapment (arrested flight) in depression: an exploration of an evolutionary view. Psychol. Med. 28, 585-598.

Gonzalez-Seijo, J.C., Vicente, Y.M.R., Martinez, I.L., Vega, J.L.D., Masia, C.C., 1996. Family factors in adolescent suicide attempts. Actas Luso-Espanolas Neurol. Psiquiatr. Y Ciencias Afines 24, 12-18.

Hardt, J., Herke, M., Schier, K., 2011. Suicidal ideation, parent-child relationships, and adverse childhood experiences: A cross-validation study using a Graphical Markov Model. Child Psychiatry Hum. Dev. 42, 119-133. https://doi.org/10.1007/s10578-0100203-4

Heider, D., Bernert, S., Matschinger, H., Haro, J.M., Alonso, J., Angermeyer, 2007. Parental bonding and suicidality in adulthood. Aust. New Zeal. J. Psychiatry 41, 66-73. https://doi.org/10.1080/00048670601057742

Hemming, L., Taylor, P., Haddock, G., Shaw, J., Pratt, D., 2019. A systematic review and meta-analysis of the association between alexithymia and suicide ideation and behaviour. J. Affect. Disord. 254, 34-48. https://doi.org/10.1016/J.JAD.2019.05.013

Jobes, D.A., Mann, R.E., 1999. Reasons for Living versus Reasons for Dying: Examining the Internal Debate of Suicide. Suicide Life $\square$ Threatening Behav. 29, 97-104. 
https://doi.org/10.1111/J.1943-278X.1999.TB01048.X

Joiner, T., 2005. Why people die by suicide. Harvard University Press, Cambridge, MA.

Karreman, A., Vingerhoets, A. J.J.M., 2012. Attachment and well-being: The mediating role of emotion regulation and resilience. Personal. Indiv. Diff. 53, 821-826. http://dx.doi.org/10.1016/j.paid.2012.06.014

Kench, S., Irwin, H.J., 2000. Alexithymia and childhood family environment. J. Clin. Psychol. 56, 737-745. https://doi.org/10.1002/(SICI)10974679(200006)56:6<737::AID-JCLP4>3.0.CO;2-U

Larose, S., Guay, F., Boivin, M., 2002. Attachment, social support, and loneliness in young adulthood: A test of two models. Personal. Soc. Psychol. Bull. 28, 684-693. https://doi.org/10.1177/0146167202288012

Leary, M.R., Guadagno, J., 2011. The sociometer, self-esteem, and the regulation of interpersonal behavior, in: Vohs, K.D., Baumeister, R.F. (Eds.), Handbook of SelfRegulation: Research, Theory, and Applications. The Guildfor Press, New York, pp. $339-354$.

Linehan, M.M., 1993. Cognitive-behavioral treatment of borderline personality disorder, 1st ed. The Guildfor Press, New York.

Locke, K.D., 2008. Attachment styles and interpersonal approach and avoidance goals in everyday couple interactions. Pers. Relatsh. 15, 359-374. https://doi.org/10.1111/j.14756811.2008.00203.x

Mikulincer, M., 1998. Attachment working models and the sense of trust: An exploration of interaction goals and affect regulation. J. Pers. Soc. Psychol. 74, 1209-1224. https://doi.org/10.1037/0022-3514.74.5.1209

Mikulincer, M., Shaver, P.R., 2011. Adult attachment and caregiving: Individual differences in providing a safe haven and secure base to others, in: Brown, S.L., Brown, R.M., Penner, L.A. (Eds.), Selfinterest and beyond: Toward a New Understanding of Human Caregiving. Oxford University Press, New York, pp. 39-52.

Mikulincer, M., Shaver, P.R., 2016a. An Attachment Perspective on Interpersonal Regulation, in: Mikulincer, M., Shaver, P.R. (Eds.), Attachment in Adulthood: Structure, Dynamics, and Change. New York, pp. 261-298. 
Mikulincer, M., Shaver, P.R., 2016b. Attachment Processes and Couple Functioning, in: Mikulincer, M., Shaver, P.R. (Eds.), Attachment in Adulthood: Structure, Dynamics, and Change. The Guildfor Press, New York, pp. 299-346.

Mikulincer, M., Shaver, P.R., 2016c. Normative attachment process, in: Mikulincer, M., Shaver, P.R. (Eds.), Attachment in Adulthood: Structure, Dynamics, and Change. The Guildfor Press, New York, pp. 47-76.

Murray, S.L., 2005. Regulating the risks of closeness: A relationship-specific sense of felt security. Curr. Dir. Psychol. Sci. 14, 74-78. https://doi.org/10.1111/j.09637214.2005.00338.x

O’Connor, R.C., 2011. Towards an Integrated Motivational-Volitional Model of Suicidal Behaviour, in: O’Connor, R.C., Platt, S., Gordon, J. (Eds.), International Handbook of Suicide Prevention. John Wiley \& Sons, Ltd, Chichester, UK, pp. 181-198. https://doi.org/10.1002/9781119998556.ch11

O'Connor, R.C., Kirtley, O.J., 2018. The integrated motivational-volitional model of suicidal behaviour. Philos. Trans. R. Soc. B Biol. Sci. 373, 20170268. https://doi.org/10.1098/rstb.2017.0268

O’Connor, R.C., Nock, M.K., 2014. The psychology of suicidal behaviour. The Lancet Psychiatry 1, 73-85. https://doi.org/10.1016/S2215-0366(14)70222-6

O’Connor, R.C., Smyth, R., Ferguson, E., Ryan, C., Williams, J.M.G., 2013. Psychological processes and repeat suicidal behavior: A four-year prospective study. J. Consult. Clin. Psychol. 81, 1137-1143. https://doi.org/10.1037/a0033751

Saffrey, C., Ehrenberg, M., 2007. When thinking hurts: Attachment, rumination, and postrelationship adjustment. Pers. Relatsh. 14, 351-368. https://doi.org/10.1111/j.14756811.2007.00160.x

Schuppert, H.M., Albers, C.J., Minderaa, R.B., Emmelkamp, P.M.G., Nauta, M.H., 2015. Severity of Borderline Personality Symptoms in Adolescence: Relationship With Maternal Parenting Stress, Maternal Psychopathology, and Rearing Styles. J. Pers. Disord. 29, 289-302. https://doi.org/10.1521/pedi_2104_28_155

Selcuk, E., Zayas, V., Günaydin, G., Hazan, C., Kross, E., 2012. Mental representations of attachment figures facilitate recovery following upsetting autobiographical memory recall. J. Pers. Soc. Psychol. 103, 362-378. https://doi.org/10.1037/a0028125 
Smith, J.A., Flowers, P., Larkin, M., 2009. Interpretative Phenomenological Analysis: Theory, Method and Research, 1st ed, Learning. Sage Publications, London.

Smith, J.A., Osborn, M., 2003. Interpretative Phenomenological Analysis, in: Smith, J.A. (Ed.), Qualitative Psychology: A Practical Guide to Research Methods. Sage Publications, Thousand Oaks, CA, pp. 51-80.

Staples, J., Widger, T., 2012. Situating Suicide as an Anthropological Problem: Ethnographic Approaches to Understanding Self-Harm and Self-Inflicted Death. Cult. Med. Psychiatry 36, 183-203. https://doi.org/10.1007/s11013-012-9255-1

Trad, P. V., 1994. The association between early life mental representations and suicidal behavior. Child Psychiatry Hum. Dev. 24, 201-212. https://doi.org/10.1007/BF02353197

Van Orden, K., Witte, T., Cukrowicz, K., Braithwaite, S., Selby, E., Joiner, T., 2010. The Interpersonal Theory of Suicide. Psychol. Rev. 117, 575-600. https://doi.org/http://dx.doi.org/10.1037/a0018697

Venta, A., Mellick, W., Schatte, D., Sharp, C., 2014. Preliminary Evidence that Thoughts of Thwarted Belongingness Mediate the Relations Between Level of Attachment Insecurity and Depression and Suicide-Related Thoughts in Inpatient Adolescents. J. Soc. Clin. Psychol. 33, 428-447. https://doi.org/10.1521/jscp.2014.33.5.428

Wedig, M.M., Nock, M.K., 2007. Parental expressed emotion and adolescent self-injury. J. Am. Acad. Child Adolesc. Psychiatry 46, 1171-1178. https://doi.org/10.1097/chi.0b013e3180ca9aaf

World Health Organization, 2014. Preventing suicide: A global imperative. Geneva, Switzerland.

Zortea, T.C., Gray, C.M., O’Connor, R.C., 2018. The relationship between adult attachment and suicidal thoughts and behaviors: A systematic review. Manuscript submitted for publication. 
Table 1. Participants' characteristics and suicidal behaviour history. Names are pseudonyms.

\begin{tabular}{|c|c|c|c|c|c|c|c|c|c|}
\hline \multirow{2}{*}{ Information } & \multicolumn{9}{|c|}{ Participants } \\
\hline & Chris & Emily & Claire & Tom & Matt & Laura & Christina & Joanne & Leon \\
\hline Gender & Male & Female & Female & Male & Male & Female & Female & Female & Male \\
\hline Age & 20 & 29 & 25 & 23 & 27 & 22 & 23 & 22 & 30 \\
\hline Ethnicity & White & White & Latin American & White & White & Asian & White & White & White \\
\hline Marital Status & $\begin{array}{l}\text { Never } \\
\text { married }\end{array}$ & $\begin{array}{l}\text { Never } \\
\text { married }\end{array}$ & Engaged & $\begin{array}{l}\text { Never } \\
\text { married }\end{array}$ & $\begin{array}{l}\text { Never } \\
\text { married }\end{array}$ & $\begin{array}{l}\text { Never } \\
\text { married }\end{array}$ & $\begin{array}{l}\text { Never } \\
\text { married }\end{array}$ & $\begin{array}{l}\text { Never } \\
\text { married }\end{array}$ & $\begin{array}{l}\text { Never } \\
\text { married }\end{array}$ \\
\hline Live with & Alone & Group home & $\begin{array}{l}\text { Academic } \\
\text { institution }\end{array}$ & $\begin{array}{l}\text { With } \\
\text { flatmate }\end{array}$ & $\begin{array}{l}\text { With } \\
\text { flatmates }\end{array}$ & With parents & With friends & Alone & $\begin{array}{l}\text { With } \\
\text { flatmates }\end{array}$ \\
\hline Education & $\begin{array}{l}\text { Highers/ } \\
\text { A-levels }\end{array}$ & Degree & $\begin{array}{l}\text { Postgraduate } \\
\text { qualification }\end{array}$ & Degree & Degree & Degree & Degree & Degree & Degree \\
\hline Sexual Orientation & Bisexual & Heterosexual & Bisexual & Heterosexual & Heterosexual & Heterosexual & Lesbian & Heterosexual & Heterosexual \\
\hline $\begin{array}{l}\text { Currently taking } \\
\text { psychiatric medication }\end{array}$ & No & No & No & No & No & No & Yes & No & No \\
\hline $\begin{array}{l}\text { Has ever been diagnosed } \\
\text { with mental health / } \\
\text { Diagnosis }\end{array}$ & $\begin{array}{l}\text { Yes } \\
\text { Depression }\end{array}$ & $\begin{array}{l}\text { Yes } \\
\text { Anxiety }\end{array}$ & $\begin{array}{l}\text { Yes } \\
\text { Anxiety, } \\
\text { Dermatillomania, } \\
\text { Orthorexia }\end{array}$ & $\begin{array}{l}\text { Yes } \\
\text { Depression }\end{array}$ & $\begin{array}{l}\text { Yes } \\
\text { Depression, } \\
\text { Anxiety }\end{array}$ & No & $\begin{array}{l}\text { Yes } \\
\text { Depression }\end{array}$ & $\begin{array}{l}\text { Yes } \\
\text { Chronic } \\
\text { depression }\end{array}$ & $\begin{array}{l}\text { Yes } \\
\text { Depression }\end{array}$ \\
\hline $\begin{array}{l}\text { Last time thought about } \\
\text { suicide }\end{array}$ & Past year & Past year & Past year & Longer ago & Longer ago & Past year & Longer ago & Past year & Longer ago \\
\hline $\begin{array}{l}\text { Age when first thought } \\
\text { about suicide }\end{array}$ & 16 & 11 & 13 & 14 & 13 & 22 & 13 & 22 & 18 \\
\hline $\begin{array}{l}\text { How many times has } \\
\text { thought about suicide }\end{array}$ & $\sim 20$ & $\begin{array}{l}\text { 'Throughout } \\
\text { life' }\end{array}$ & 4 & $10+$ & Multiple & 4 & $\begin{array}{l}\text { Does not } \\
\text { know }\end{array}$ & 2 & 1 \\
\hline Age when first attempted & 17 & 25 & 14 & 16 & 13 & 22 & 13 & 19 & 18 \\
\hline
\end{tabular}


suicide

Number of suicide attempts

Last time attempted suicide Past year

Does not

remember

Longer ago

Longer ago Longer ago

Longer ago

Past year

Longer ago 
Figure 1. Thematic map representing how the master themes are related to suicide risk via psychological vulnerability and resilience. Plus sign $(+)$ represents increase and minus sign (-) represents reduction/decrease. Challenging relationships contributes to the development of psychological vulnerability factors which in turn increase suicide risk. Positive relationships contribute to the development of resilience factors which in turn decrease both psychological vulnerability and suicide risk.

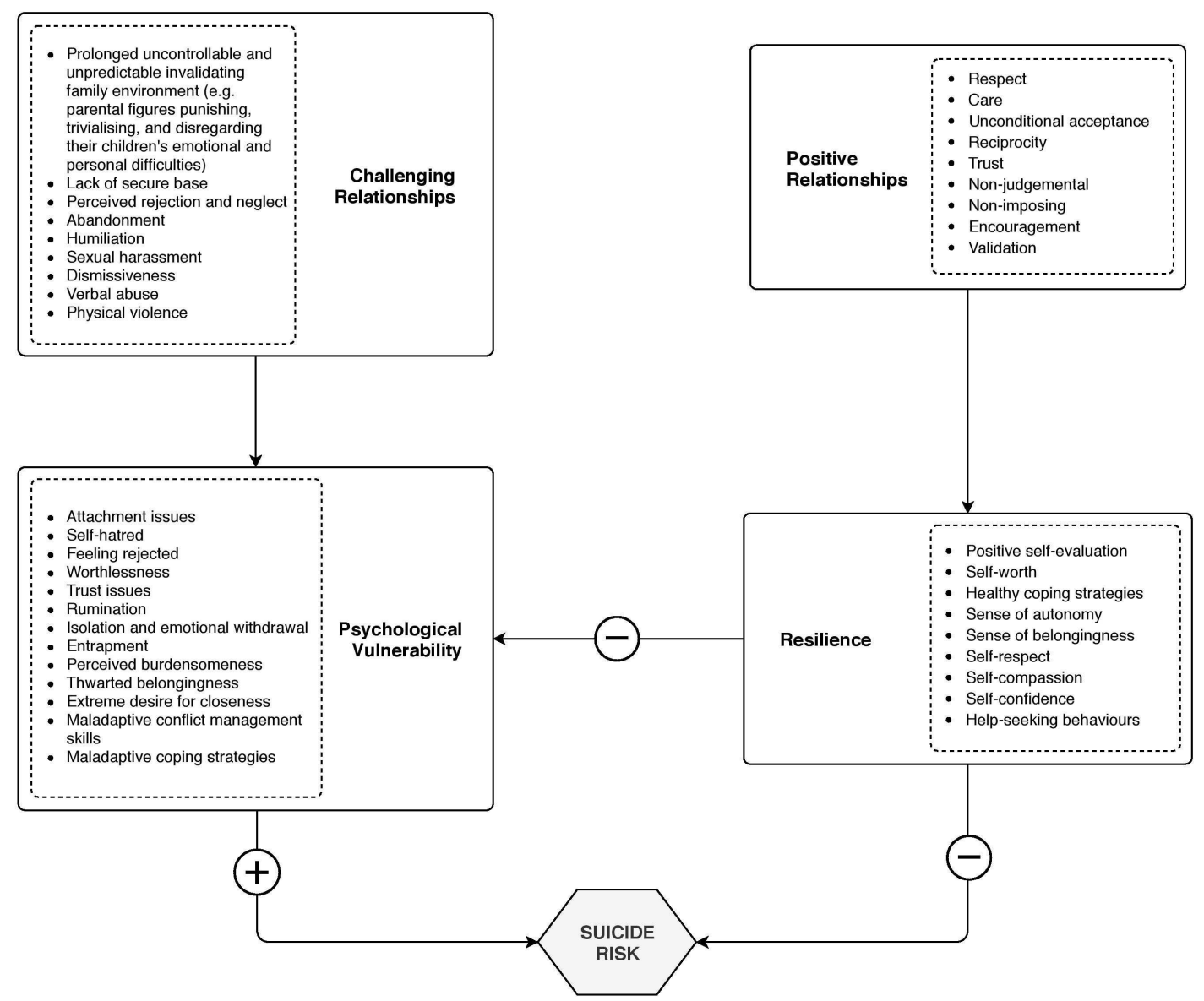




\section{Acknowledgements}

This study is funded by a scholarship from the Brazilian National Council for Scientific and Technological Development to the primary author (Process Number 203245/2014-8). This study was supported, in part, by ROC's research funding provided by University of Glasgow. The authors have no conflict of interest to declare. 


\section{Research highlights}

- Qualitative study on close relationships and suicidal thoughts and behaviours (STB).

- Early, disrupted parent-child attachments may contribute to vulnerability for STB.

- Challenging relationships may act as catalysts for STB.

- Positive relationships are associated with recovery and reduction of current STB risk.

- Theoretical and clinical implications are discussed. 